\title{
Ethanol production from xylose by recombinant Saccharomyces cerevisiae expressing protein- engineered NADH-preferring xylose reductase from Pichia stipitis
}

\author{
Correspondence \\ Seiya Watanabe \\ irab@iae.kyoto-u.ac.jp
}

Received 6 March 2007

Revised 31 May 2007

Accepted 5 June 2007

\author{
Seiya Watanabe, ${ }^{1,2,3}$ Ahmed Abu Saleh, ${ }^{2}$ Seung Pil Pack, ${ }^{2,3}$ \\ Narayana Annaluru, ${ }^{2}$ Tsutomu Kodaki ${ }^{2,3}$ and Keisuke Makino ${ }^{2,3,4}$ \\ ${ }^{1}$ Faculty of Engineering, Kyoto University, Kyotodaigaku-katsura, Saikyo-ku, Kyoto 615-8530, \\ Japan \\ ${ }^{2}$ Institute of Advanced Energy, Kyoto University, Gokasho, Uji, Kyoto 611-0011, Japan \\ ${ }^{3}$ CREST, JST (Japan Science and Technology Agency), Gokasho, Uji, Kyoto 611-0011, Japan \\ ${ }^{4}$ International Innovation Center, Kyoto University, Yoshidahonmachi, Sakyo-ku, Kyoto 606-8501, \\ Japan
}

\begin{abstract}
A recombinant Saccharomyces cerevisiae strain transformed with xylose reductase (XR) and xylitol dehydrogenase (XDH) genes from Pichia stipitis ( $P s \mathrm{XR}$ and $P s \mathrm{XDH}$, respectively) has the ability to convert xylose to ethanol together with the unfavourable excretion of xylitol, which may be due to intercellular redox imbalance caused by the different coenzyme specificity between $\mathrm{NADPH}$-preferring $\mathrm{XR}$ and $\mathrm{NAD}^{+}$-dependent $\mathrm{XDH}$. In this study, we focused on the effect(s) of mutated NADH-preferring PsXR in fermentation. The R276H and K270R/N272D mutants were improved 52- and 146-fold, respectively, in the ratio of NADH/NADPH in catalytic efficiency $\left[\left(k_{\text {cat }} / K_{\mathrm{m}}\right.\right.$ with $\left.\mathrm{NADH}\right) /\left(k_{\mathrm{cat}} / K_{\mathrm{m}}\right.$ with NADPH)$\left.)\right]$ compared with the wild-type $(\mathrm{WT})$, which was due to decrease of $k_{\text {cat }}$ with NADPH in the R276H mutant and increase of $K_{\mathrm{m}}$ with NADPH in the K270R/N272D mutant. Furthermore, R276H mutation led to significant thermostabilization in PsXR. The most positive effect on xylose fermentation to ethanol was found by using the Y-R276H strain, expressing PSXR R276H mutant and PSXDH WT: $20 \%$ increase of ethanol production and $52 \%$ decrease of xylitol excretion, compared with the Y-WT strain expressing $P s X R$ WT and PsXDH WT. Measurement of intracellular coenzyme concentrations suggested that maintenance of the of NADPH/NADP ${ }^{+}$and NADH/NAD ${ }^{+}$ratios is important for efficient ethanol fermentation from xylose by recombinant $S$. cerevisiae.
\end{abstract}

\section{INTRODUCTION}

Xylose is one of the major fermentable sugars present in lignocellulosic biomass, the second most abundant carbohydrate polymer in nature after glucose. The efficient fermentation of xylose is required to develop economically viable processes for producing biofuels such as ethanol from biomass (Jeffries \& Jin, 2004). Although a few xylosefermenting yeasts are found in nature (Jeffries, 1983; Kurtzman, 1994), Saccharomyces cerevisiae is used universally

Abbreviations: AKR, aldo-keto reductase; $\mathrm{CD}$, circular dichroism; PGK, phosphoglycerate kinase; $\mathrm{XDH}$, xylitol dehydrogenase; PsXDH, XDH from Pichia stipitis; $\mathrm{XI}$, xylose isomerase; $\mathrm{XR}$, xylose reductase; $\mathrm{Ct} \mathrm{XR}, \mathrm{XR}$ from Candida tenuis; PsXR, XR from Pichia stipitis; $T_{m}$, thermal unfolding transition temperature; WT, wild-type.

Two supplementary tables are available with the online version of this paper. for industrial ethanol production because of its ability to produce high concentrations of ethanol and high inherent ethanol tolerance; however, native $S$. cerevisiae can not ferment xylose, so engineering $S$. cerevisiae for xylose utilization has focused on adapting the xylose metabolic pathway from the xylose-utilizing yeast Pichia stipitis. In this organism, xylose is converted to xylulose by two oxidoreductases: xylose is initially reduced to xylitol by $\mathrm{NAD}(\mathrm{P}) \mathrm{H}$-linked xylose reductase (XR; EC 1.1.1.21) (Verduyn et al., 1985), and then xylitol is oxidized to xylulose by $\mathrm{NAD}^{+}$-linked xylitol dehydrogenase $(\mathrm{XDH}$; EC 1.1.1.9) (Rizzi et al., 1989). Finally, xylulokinase (EC 2.7.1.17) phosphorylates xylulose into xylulose 5phosphate, which is metabolized further via the pentosephosphate pathway.

Although S. cerevisiae transformed with native XYL1 and $X Y L 2$ genes encoding $\mathrm{XR}$ and $\mathrm{XDH}$ from $P$. stipitis 
(referred to as PsXR and $P s \mathrm{XDH}$, respectively) and the endogenous $X Y L 3$ gene encoding xylulokinase was the most potent recombinant strain, its ethanol production was not sufficient for application in the industrial bioprocess. One of the main reasons is the unfavourable excretion of xylitol, which may be due to intracellular redox imbalance caused by the different coenzyme specificity between XR and XDH (Jeffries \& Jin, 2004). On the other hand, in bacteria, xylose is directly converted with no coenzyme by xylose isomerase (XI, EC 5.3.1.5): this is one solution to the redox balance issue. However, no significant XI activity had been attained in transformed $S$. cerevisiae cells, except a thermophilic enzyme. Furthermore, the energetics of isomerization between xylose and xylulose favours xylose formation (Jeffries, 1985). Therefore, modifying the coenzyme specificity of XR and/or XDH by protein engineering is one of the attractive challenges for achieving efficient ethanol fermentation from xylose using S. cerevisiae. In the case of XDH, Metzger \& Hollenberg (1995) first attempted to identify a set of amino acid residues in $P S \mathrm{XDH}$ responsible for specificity to $\mathrm{NAD}^{+}$. They introduced the potential $\mathrm{NADP}^{+}(\mathrm{H})-$ recognition sequence of Escherichia coli glutathione reductase (no homology with $P s \mathrm{XDH}$ ) and thermophilic alcohol dehydrogenase $(\sim 30 \%$ homology) into the homologous sequence in PsXDH. However, the mutant enzyme(s) had decreased XDH activity $(\sim 40 \%)$ and still preferred $\mathrm{NAD}^{+}$ to $\mathrm{NADP}^{+}$, although an approximately 10 -fold increase in $K_{\mathrm{m}}$ with $\mathrm{NAD}^{+}$was found. In an alternative approach, we used the unique $\mathrm{NADP}^{+}(\mathrm{H})$-dependent sorbitol dehydrogenase as a reference enzyme and achieved complete reversal of coenzyme specificity toward $\mathrm{NADP}^{+}$ (Watanabe et al., 2005). Furthermore, when the novel $\mathrm{NADP}^{+}$-dependent $\mathrm{XDH}$ mutant was co-expressed with $P s \mathrm{XR}$ in S. cerevisiae cells, effective ethanol fermentation and a reduction in xylitol excretion were found, probably due to maintenance of the intracellular redox balance (Watanabe et al., 2007). To our knowledge, this is the first report of improving ethanol fermentation from xylose by the protein engineering of $\mathrm{XDH}$.

Jeppsson et al. (2006) reported that enhanced ethanol yield accompanied by decreased xylitol excretion was found in recombinant S. cerevisiae carrying the K270M PsXR mutant with increased $K_{\mathrm{m}}$ for NADPH (Kostrzynska et al., 1998) together with PsXDH WT. This is the first improvement of ethanol fermentation from xylose by the protein engineering of XR. In the protein engineering of XR, the enzyme from Candida tenuis (CtXR) has recently been studied extensively (Kavanagh et al., 2002, 2003; Leitgeb et al., 2005; Petschacher \& Nidetzky, 2005; Petschacher et al., 2005), although the effect of expression of the mutant(s) generated has not been reported. XR belongs to the aldoketo reductase (AKR) superfamily (Ellis, 2002). Although most members of this superfamily show strong dependence on NADPH, a few members including XR (AKR2B5), $3 \alpha-$ hydroxysteroid dehydrogenase (AKR1C9) and 3-dehydroecdysone $3 \beta$-reductase (AKR2E1) can utilize both
NADH and NADPH (Ellis, 2002). Furthermore, the crystal structures of $C t \mathrm{XR}$ bound to $\mathrm{NAD}^{+}$or $\mathrm{NADP}^{+}$were the first to be resolved among AKR superfamily enzymes (Kavanagh et al., 2002, 2003). Based on this useful information, we generated several NADH-preferring PsXR mutants by site-directed mutagenesis and then constructed recombinant yeasts co-expressing XYL1 genes encoding mutated PsXR and XYL2 genes encoding WT $P s X D H$. The resultant recombinant yeasts were characterized for their enzyme activity and the ability to ferment xylose to ethanol.

\section{METHODS}

Materials and media. S. cerevisiae D452-2 (MATa leu2 his3 ura3 can1) (Kurtzman, 1994) was used as the recipient yeast strain for the expression of $P s \mathrm{XDH}$ and PsXR. S. cerevisiae was grown in yeastpeptone-glucose [dextrose] (YPD) medium (10 g yeast extract, $20 \mathrm{~g}$ peptone and $20 \mathrm{~g}$ glucose per litre) and in a defined minimal medium (6.7 $\mathrm{g} \mathrm{l}^{-1}$ yeast nitrogen base without amino acids). Glucose $\left(5 \mathrm{~g} \mathrm{l}^{-1}\right)$ and/or xylose $\left(15 \mathrm{~g} \mathrm{l}^{-1}\right)$ was added to the minimal medium in fermentation experiments. Leucine, histidine and uracil were added at 20, 20 and $5 \mathrm{mg} \mathrm{l}^{-1}$, respectively, when necessary.

Enzyme assays. Activities of $\mathrm{XR}$ and $\mathrm{XDH}$ were assayed by the method described previously (Watanabe et al., 2007, 2005). The kinetic parameters $K_{\mathrm{m}}$ and $k_{\text {cat }}$ were calculated by Lineweaver-Burk plots. Protein concentrations were determined by the Lowry method with BSA as the standard.

SDS-PAGE and Western blot analysis. SDS-PAGE was carried out by the method of Laemmli (1970) with $12 \%$ acrylamide gels at $25 \mathrm{~mA}$. For Western blot analysis, cell-free extracts of E. coli and/or purified PsXRs were separated by SDS-PAGE, and the proteins on the gels were transferred onto a nitrocellulose membrane (Hybond-ECL; Amersham Biosciences). Western blot analysis was carried out with the ECL-Western blotting detection system (Amersham Biosciences) and RGS·His HRP antibody, a horseradish-peroxidase-fused mouse monoclonal antibody against Arg-Gly-Ser-(His) ${ }_{6}$ in the N-terminal additive peptide of expressed recombinant proteins (Qiagen).

Cloning of the $P$. stipitis $X Y L 1$ gene and construction of recombinant plasmids. Pichia stipitis (Yamadazyma stipitis NBRC 1687) was purchased from the National Institute of Technology and Evaluation (Chiba, Japan). P. stipitis genomic DNA was isolated according to the method described previously (Watanabe et al., 2005). Based on the published sequence of the P. stipitis XYL1 gene (GenBank accession no. X59465), two primers were designed as follows: XR-UP1 (5'-ATGCCTTCTATTAAGTTGAACTCTGG-3') and XR-DOWN1 (5'-TTAGACGAAGATAGGAATCTTGTCCC-3'). PCR was carried out using a PCR Thermal Cycler PERSONAL $(\mathrm{TaKaRa})$ in a $50 \mu \mathrm{l}$ reaction mixture containing $10 \mathrm{pmol}$ primers, $1 \mathrm{U}$ KOD-plus DNA polymerase (Toyobo) and $100 \mathrm{ng}$ P. stipitis genomic DNA under the following conditions: denaturation at $94{ }^{\circ} \mathrm{C}$ for $15 \mathrm{~s}$, annealing at $50{ }^{\circ} \mathrm{C}$ for $30 \mathrm{~s}$ and extension at $68{ }^{\circ} \mathrm{C}$ for $1.5 \mathrm{~min}$. The amplified DNA fragment was introduced into the SmaI site in the plasmid pBluescript SK(-) (Stratagene), to yield pBS-XYL1. To introduce the restriction sites for BamHI and PstI at the $5^{\prime}$ - and $3^{\prime}$-termini, respectively, of the XYL1 gene, PCR was carried out using pBS-XYL1 as template DNA and the following two primers: XRUP2 ( $5^{\prime}$-catacggatccTTCTATTAAGTTGAAC- $\left.3^{\prime}\right)$ and XR-DOWN2 (5'-cttggctgcagTTAGACGAAGATAGG-3') [small letters indicate additional bases for introducing BamHI and PstI digestion sites (underlined)]. The amplified DNA fragment was introduced into the 
BamHI/PstI sites in pQE-81L (Qiagen), a plasmid vector for adding an $\mathrm{N}$-terminal (His) ${ }_{6}$-tag on expressed proteins, to obtain $\mathrm{pHis}(\mathrm{WT})$.

Site-directed mutagenesis of PsXR. The mutations were introduced by single-round PCR with a small modification. The synthetic oligonucleotide primer sequences used for the PsXR mutations are shown in Supplementary Table S1, available with the online version of this paper. Briefly, the codons used for single mutants are as follows: K270R (AAG $\rightarrow$ AGA), K270G $($ AAG $\rightarrow$ GGT), N272D (AAC $\rightarrow$ GAC) and $\mathrm{R} 276 \mathrm{H}(\mathrm{AGA} \rightarrow \mathrm{CAC})$. Every double and triple mutant was made using these single mutations. The nicked circular strands with mutation in the XYL1 gene, which is contained in a plasmid template, were amplified using 22-25 bp sense and antisense primers containing the mutation (described above) with LA Taq DNA polymerase (TaKaRa) under the following conditions: denaturation at $94{ }^{\circ} \mathrm{C}$ for $10 \mathrm{~s}$, annealing and extension at $68{ }^{\circ} \mathrm{C}$ for $6 \mathrm{~min}$ (30 cycles). PCR products were incubated with $D p n \mathrm{I}$ at $37{ }^{\circ} \mathrm{C}$ for $1 \mathrm{~h}$. This treatment ensured the digestion of the Dam-methylated parental strand, which was used as the PCR template. The remaining nicked circular mutagenic strands were transformed into E. coli $\mathrm{DH} 5 \alpha$, where bacterial DNA ligase repaired the nick and allowed normal replication to occur. The whole coding region of all mutated genes was sequenced in both directions using a Dual CyDye Terminator Sequencing kit (Veritas) and appropriate primers with a Long-Read Tower, UBC DNA sequencer (Amersham Biosciences): only appropriate muta$\operatorname{tion}(\mathrm{s})$ were found.

Overexpression and purification of $(\mathbf{H i s})_{6}$-tagged enzymes. $E$. coli $\mathrm{DH} 5 \alpha$ harbouring the expression plasmid for the (His) ${ }_{6}$-tagged WT and mutated PsXRs were grown at $37{ }^{\circ} \mathrm{C}$ to $\mathrm{OD}_{600}$ 0.6in Super broth medium (per litre: $12 \mathrm{~g}$ tryptone, $24 \mathrm{~g}$ yeast extract, $5 \mathrm{ml}$ glycerol, $3.81 \mathrm{~g} \mathrm{KH}_{2} \mathrm{PO}_{4}$ and $12.5 \mathrm{~g} \mathrm{~K}_{2} \mathrm{HPO}_{4} ; \mathrm{pH}$ 7.0) containing $50 \mathrm{mg}$ ampicillin $\mathrm{1}^{-1}$. The cultures were then rapidly cooled on ice, added to $1 \mathrm{mM}$ IPTG and further incubated for $24 \mathrm{~h}$ at $18{ }^{\circ} \mathrm{C}$ to induce the expression of PSXR protein. Cells were harvested and resuspended in $20 \mathrm{ml}$ buffer A (50 mM sodium phosphate, $\mathrm{pH} 6.0$, containing $0.3 \mathrm{M} \mathrm{NaCl}, 10 \mathrm{mM}$ xylose, $5 \mathrm{mM}$ 2-mercaptoethanol and $10 \mathrm{mM}$ imidazole) per litre of culture. The cells were then disrupted by sonication for a total of $4-5 \mathrm{~min}$, with cooling intervals on ice, using an ASTRASON Ultrasonic Liquid Processor XL2020 (Misonix), and the cell lysate was centrifuged to remove cell debris. All chromatography was carried out using the ÄKTA purifier system (Amersham Biosciences) at $4{ }^{\circ} \mathrm{C}$. The resultant supernatant was loaded onto a Ni-NTA Superflow column (Qiagen) equilibrated with buffer A. After washing with the same buffer, the column was further washed with buffer B (buffer A containing $10 \%, \mathrm{v} / \mathrm{v}$, glycerol and $50 \mathrm{mM}$ instead of $10 \mathrm{mM}$ imidazole). The enzymes were then eluted with buffer C (buffer B containing $250 \mathrm{mM}$ instead of $50 \mathrm{mM}$ imidazole). The eluate was treated by ultrafiltration with Centriplus YM-30 (Millipore) and loaded onto a HiLoad 16/60 Superdex 200 pg column (Amersham Biosciences) equilibrated with buffer D $(50 \mathrm{mM}$ sodium phosphate, $\mathrm{pH} 6.0$, containing $10 \mathrm{mM}$ xylose and $5 \mathrm{mM} \mathrm{2-}$ mercaptoethanol). The peak fraction corresponding to PsXR was pooled, treated by ultrafiltration and dialysed against buffer $\mathrm{E}$ (50 mM sodium phosphate, $\mathrm{pH} 6.0$, containing $10 \mathrm{mM}$ xylose, $5 \mathrm{mM} 2$-mercaptoethanol and $50 \%$, w/v, glycerol). All (His) ${ }_{6}$-tagged recombinant PsXRs were stored at $-35{ }^{\circ} \mathrm{C}$ until use.

Enzyme stability. To estimate the effect of site-directed mutagenesis in thermostability, circular dichroism (CD) and heat-inactivation analysis were carried out. Enzyme samples dialysed overnight against buffer $\mathrm{F}$ ( $50 \mathrm{mM}$ sodium phosphate, $\mathrm{pH} 6.0$, containing $5 \mathrm{mM} \mathrm{2-}$ mercaptoethanol) were diluted to concentrations of $2 \mathrm{mg} \mathrm{ml}^{-1}$ with the same buffer. $\mathrm{CD}$ at $220 \mathrm{~nm}$ was measured between $10{ }^{\circ} \mathrm{C}$ and $50{ }^{\circ} \mathrm{C}$ with a Jasco spectropolarimeter model J-720 (Japan Spectroscopic Co.), equipped with temperature-controlled cell holders, using a quartz cuvette with a path length of $2 \mathrm{~mm}$ under constant $\mathrm{N}_{2}$ flush. Temperature was increased at a rate of $1{ }^{\circ} \mathrm{C} \mathrm{min}-1$. The thermal transition temperature $\left(T_{\mathrm{m}}\right)$ was determined using Jasco software. For heat-inactivation analysis, the enzyme sample was incubated at $30{ }^{\circ} \mathrm{C}$ for $10 \mathrm{~min}$ and the remaining activity was measured under standard assay conditions.

\section{Construction of vectors overexpressing $X Y L 1$ and $X Y L 2$ genes} in $\mathbf{S}$. cerevisiae. The $X Y L 1$ and $X Y L 2$ genes were expressed constitutively under the control of the phosphoglycerate kinase (PGK) promoter and terminator. To introduce a restriction site for HindIII and BamHI at the $5^{\prime}$ - and $3^{\prime}$-termini, respectively, of the XYL1 gene, PCR was carried out using pBS-XYL1 as template DNA and the following two primers: XR-UP3 (5'-catcgacaagcttATGCCTTCTATTAAGTTGAACTCTGG-3') and XR-DOWN3 $\left(5^{\prime}\right.$ gtcgatgggatccTTAGACGAAGATAGGAATCTTGTCCC-3') [small letters indicate additional bases for introducing HindIII and BamHI digestion sites (underlined)]. The amplified DNA fragment was introduced into the HindIII/BamHI sites between the PGK expression cassettes in plasmid pPGK (Kang et al., 1990) to obtain pPGK$\mathrm{XR}$ (pre-WT). To eliminate two restriction sites for SalI in the XYL1 gene, single-round PCR was performed by LA Taq DNA polymerase using pPGK-XR(pre-WT) as template DNA and the following two primers: $\Delta$ SalI-S (5'-GTTGGAAAGTTGACGTTGACACCTGTTC$\left.3^{\prime}\right)$ and $\triangle$ SalI-AS (5'-GAACAGGTGTCAACGTCAACTTTCCAAC$3^{\prime}$ ) (underlining indicates mutated regions). The substitution of Sall sites in the XYL1 gene resulted in no change of amino acid residues. After treatment with $D p n I$, PCR products were transformed into $E$. coli DH5 $\alpha$ to obtain plasmid pPGK-XR(WT). The $\sim 2.0 \mathrm{kbp}$ DNA fragment comprising the XYL1 gene between the PGK expression cassettes was excised from pPGK-XR(WT) by XhoI and Sall, and introduced into the SalI site of plasmid YEpM4 (Nikawa et al., 1987), resulting in YEpM4-XR(WT). Site-directed mutagenesis of the XYL1 gene in plasmid YEpM4-XR(WT) (K270R, R276H and K270R/ $\mathrm{N} 272 \mathrm{D})$ was performed by single-round PCR with the same procedure as for the $\mathrm{pQE}-81 \mathrm{~L}$ series.

To introduce a restriction site for EcoRI and BamHI at the $5^{\prime}$ - and $3^{\prime}$ termini, respectively, of the XYL2 gene, PCR was carried out using pBS-XYL2 [pBluescript SK(-) containing the XYL2 gene] (Watanabe et al., 2005) as a template DNA and the following two primers: $\mathrm{XDH}$ UP (5'-catcgacgaattcATGACTGCTAACCCTTCCTTGGTGTTG-3') and XDH-DOWN (5' -gtcgatgggatccTTACTCAGGGCCGTCAATGAGACACTTG-3') (small letters indicate additional bases for introducing EcoRI and BamHI digestion sites (underlined)]. The amplified DNA fragment was introduced into the EcoRI/BamHI sites between the PGK expression cassettes in plasmid pPGK to obtain pPGK-XDH.

Yeast transformation. This was performed by the lithium acetate method (Gietz et al., 1992). S. cerevisiae D452-2 was transformed with pPGK-XDH and then further transformed with YEpM4-XR(WT), YEpM4-XR(R276H) and YEpM4-XR(K270R/N272D) to construct recombinant yeast strains Y-WT, Y-R276H and Y-K270R/N272D, respectively. Both empty vectors, pPGK and YEpM4, were transformed into S. cerevisiae D452-2 to construct a control strain (Y-Vector).

Preparation of cell-free extract. The recombinant yeast strains were grown in minimal medium supplemented with glucose as sole carbon source at $30{ }^{\circ} \mathrm{C}$. The cells were harvested, resuspended in $100 \mathrm{mM}$ sodium phosphate, $\mathrm{pH} 7.0$, containing $1 \mathrm{mM} \mathrm{MgCl}_{2}$, $0.5 \mathrm{mM}$ EDTA and $0.5 \mathrm{mM}$ dithiothreitol, and vortexed together with an equal volume of glass beads $(0.5 \mathrm{~mm}$ diameter $)$. Cell debris and glass beads from the cell extract were separated by centrifugation and the remaining supernatant was used for enzyme determinations.

Preliminary batch fermentation in shake flasks. After precultivation of recombinant yeast strains in $3 \mathrm{ml}$ minimal medium for 3 days, 
yeast cells were aerobically cultivated for 3 days at $30{ }^{\circ} \mathrm{C}$ in $100 \mathrm{ml}$ minimal medium supplemented with 5 g glucose $\mathrm{l}^{-1}$ and $15 \mathrm{~g}$ xylose $1^{-1}$ with shaking at 200 r.p.m. Cell pellets were collected by centrifugation, washed with $\mathrm{NaCl}$ solution $\left(9 \mathrm{~g} \mathrm{l}^{-1}\right)$ and inoculated into $200 \mathrm{ml}$ fermentation medium. Ethanol fermentation was carried out as batch cultures in a $200 \mathrm{ml}$ flask sealed with two layers of Saran wrap (under oxygen-limiting conditions) in an incubator at 150 r.p.m. Samples $(1 \mathrm{ml})$ of the fermentation broth were removed at intervals and stored at $-35{ }^{\circ} \mathrm{C}$ to analyse substrates and fermentation products.

Batch fermentation in a bioreactor. A high-performance bioreactor (BioFlo 110, New Brunswick Scientific Co.) was used for oxygen-limiting batch fermentation. S. cerevisiae cells were prepared by similar procedures to those for fermentation in shake flasks except that the culture volume was $300 \mathrm{ml}$. Cell pellets obtained by centrifugation were inoculated into 1 litre minimal medium supplemented with $5 \mathrm{~g}$ glucose $\mathrm{l}^{-1}$ and $15 \mathrm{~g}$ xylose $\mathrm{l}^{-1}$ with shaking at 200 r.p.m. and transferred into a 1.3 litre bioreactor. Temperature was maintained at $30{ }^{\circ} \mathrm{C}$ and $\mathrm{pH}$ was controlled at 5.5 by the addition of $2 \mathrm{M} \mathrm{NaOH}$ and $1 \mathrm{M} \mathrm{H}_{2} \mathrm{SO}_{4}$. The agitation speed was constant at 500 r.p.m.

Measurement of intracellular coenzyme contents. Intracellular coenzymes were extracted from cells growing under oxygen-limiting conditions in minimal medium with $10 \mathrm{~g}_{\text {xylose }} \mathrm{l}^{-1}$ plus $10 \mathrm{~g}$ glucose $\mathrm{l}^{-1}$. A $20 \mathrm{ml}$ sample of yeast culture was withdrawn and sprayed into $80 \mathrm{ml} 60 \%(\mathrm{v} / \mathrm{v})$ methanol at $-40{ }^{\circ} \mathrm{C}$. After this quenching step, coenzymes were extracted in $50 \mathrm{mM}$ potassium phosphate $(\mathrm{pH} 5.0)$ (for $\mathrm{NAD}^{+}$and $\mathrm{NADP}^{+}$) or $50 \mathrm{mM}$ Tris/HCl (pH 9.0) (for $\mathrm{NADH}$ and NADPH). The contents of $\mathrm{NAD}^{+}, \mathrm{NADH}, \mathrm{NADP}^{+}$and NADPH in the samples were determined by monitoring the absorbance difference at $339 \mathrm{~nm}$ using the followed coupling enzymes at room temperature (Bergmeyer, 1985): for $\mathrm{NAD}^{+}$, alcohol dehydrogenase (from baker's yeast, Sigma); for $\mathrm{NADP}^{+}$, glucose-6-phosphate dehydrogenase (type XV from baker's yeast, Sigma); for NADH, glycerol-3-phosphate dehydrogenase (from rabbit muscle, Wako); for $\mathrm{NADPH}$, glutamate dehydrogenase (from beef liver, Oriental Yeast).

Analysis of fermentation products. Ethanol concentration was measured by gas chromatography (model GC-14B, Shimadzu; fitted with a flame-ionization detector) under the following conditions: glass column packed with Thermon-3000 $(2.0 \mathrm{~m} \times 3.2 \mathrm{~mm}$, Shimadzu); temperature of column, $70{ }^{\circ} \mathrm{C}$; injector, $200{ }^{\circ} \mathrm{C}$; detector, $250{ }^{\circ} \mathrm{C}$; and nitrogen carrier gas flow rate, $25 \mathrm{ml} \mathrm{min}{ }^{-1}$. The concentrations of glucose, xylose, xylitol, glycerol and acetic acid were estimated by HPLC with a Multi-Station LC-8020 model II system (TOSOH). Samples $(100 \mu \mathrm{l})$ were applied at $30{ }^{\circ} \mathrm{C}$ to an Aminex HPX-87H Organic Analysis column $(300 \times 7.8 \mathrm{~mm}$,
Bio-Rad) linked to an RID-8020 refractive index detector (TOSOH)

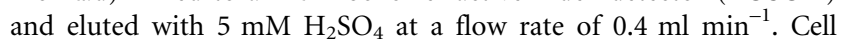
growth was monitored by measuring $\mathrm{OD}_{600}$ with a Hitachi model $\mathrm{U}$ 2001 spectrophotometer.

\section{RESULTS}

\section{Modification of coenzyme specificity of PsXR}

$\mathrm{XR}$ (AKR2B5) is a unique member, with dual coenzyme specificity, of the aldo-keto reductase (AKR) superfamily (Ellis, 2002), although significant NADPH preference is found in most XRs, similar to most AKR superfamily enzymes. In this study, we designed $\mathrm{NADH}$-preferring PsXR mutants by three different strategies based on the following observations.

(1) XR from Candida parapsilosis shows 100-fold higher utilization of NADH than NADPH in terms of catalytic efficiency; it possesses a unique arginine residue in the coenzyme-binding pocket instead of $\mathrm{Lys}^{270}$ in PsXR (Table 1) (Lee et al., 2003).

(2) Several site-directed mutagenetic and crystallographic studies for modifying coenzyme specificity toward NADH, using NADPH-preferring XR from C. tenuis ( $C t \mathrm{XR})$, were recently reported by B. Nidetzky and coworkers (Kavanagh et al., 2002, 2003; Leitgeb et al., 2005; Petschacher \& Nidetzky, 2005; Petschacher et al., 2005). This fungal XR shows $\sim 77 \%$ sequential similarity to PsXR. The K274R/ $\mathrm{N} 276 \mathrm{D}$ mutations lead to the highest ratio of NADH/ $\mathrm{NADPH}$ preference in terms of $k_{\mathrm{cat}} / K_{\mathrm{m}}$ among the series of CtXR mutants investigated, and correspond to the K270R/ R272D mutations in PsXR (Table 1).

(3) 2,5-Diketo-D-gluconic acid reductase, a member of the AKR superfamily (AKR5C1), also shows inherent NADPH specificity. However, mutations equivalent to K270G and $\mathrm{R} 276 \mathrm{H}$ in PsXR lead to efficient NADH preference (Banta et al., 2002a, b).

On the basis of the above, we generated three single mutants (K270R, K270G and R276H), three double mutants (K270R/N272D, K270R/R276H and N272D/

Table 1. Partial amino acid sequence alignment of AKRs

\begin{tabular}{|lclll|}
\hline Enzyme & Accession no. & \multicolumn{1}{c}{ Organism } & Coenzyme & \multicolumn{1}{c|}{ Sequence $\$$} \\
\hline XR & CAA42072 & P. stipitis & NADPH & 268 IPKSNTVPRLL \\
XR & AAC25601 & C. tenuis & NADPH & 272 IPKSNLPERLV \\
& & & NADH $\dagger$ & 174 IPRSDLPERLV \\
XR & AY193716 & C. parapsilosis & NADH & 274 IPRSNSPDRMA \\
2,5 -DKGRA & AAA83534 & Corynebacterium sp. & NADPH & 230 FPKSVRRERLE \\
& & & NADH $\ddagger$ & 230 FPGSVRREHLE \\
& & & & \\
\hline
\end{tabular}

*2,5-Diketo-D-gluconic acid reductase A.

$\dagger$ K274R/N276D mutant.

$\$ \mathrm{~K} 232 \mathrm{G} / \mathrm{R} 238 \mathrm{H}$ mutant.

§Bold letters correspond to mutation sites in this study. 
$\mathrm{R} 276 \mathrm{H})$ and one triple mutant (K270R/N272D/R276H) to modify the coenzyme specificity of $P_{s} X R$.

\section{Overexpression and purification of recombinant PsXR}

We initially attempted to express PsXR in E. coli cells at $37{ }^{\circ} \mathrm{C}$ because PsXR is a typical mesophilic enzyme, but after induction by IPTG, no expression was detectable by enzyme activity assay or Western blotting using an antibody against the (His) ${ }_{6}$-tag in cell-free extracts of $E$. coli (data not shown). However, the XYL1 gene was significantly induced at $18{ }^{\circ} \mathrm{C}$ by IPTG. (His) ${ }_{6}$-tagged $P_{s} \mathrm{XR}$ (WT) may be relatively thermolabile, at least in vitro (see below); therefore, all recombinant PsXRs were overexpressed under this condition and purified with a $\mathrm{Ni}^{2+}$ chelating affinity column and subsequent gel filtration. SDS-PAGE analysis revealed that the purified recombinant enzymes were almost homogeneous and the apparent molecular mass of the PsXRs was $\sim 38,000 \mathrm{Da}$, in good agreement with the calculated molecular mass of the enzyme with a (His) ${ }_{6}$-tag $(37,261.77 \mathrm{Da})$ (data not shown). Gel filtration revealed the homodimeric form of the purified recombinant enzyme as well as the native form (data not shown) (Verduyn et al., 1985). Kostrzynska et al. (1998) successfully expressed PsXR in E. coli cells even at $37^{\circ} \mathrm{C}$, although the recombinant enzyme was a non-tagged form. Recently, we also constructed an alternative expression system for (His) $)_{6}$-tagged $P s \mathrm{XR}$ at $37^{\circ} \mathrm{C}$, in which a plasmid vector based on the T7 promoter (the T5 promoter was used in the present study) and E. coli BL21(DE3) as a host cell (DH5 $\alpha$ was used in the present study) were used. Therefore, the expression of PsXR found only at low temperature in the present study may be due to the expression system rather than the inherent thermolability of the protein.

\section{Characterization of PsXR mutants in vitro}

Specific activities of the recombinant PsXR WT enzyme in the presence of NADH and NADPH (Table 2) were 7.2 and 15.7 $\mathrm{U} \mathrm{mg}^{-1}$, respectively, comparable to those of the native enzyme (16.7 and $23.2 \mathrm{U} \mathrm{mg}^{-1}$, respectively) (Verduyn et al., 1985). Among the five single mutants, $\mathrm{R} 276 \mathrm{H}$ substitution was the best for acquired NADH preference: specific activity in the presence of NADPH decreased 39-fold compared to WT, while NADH-dependent activity was similar to NADH-dependent activity in WT. The K270R mutant showed higher specific activity with NADPH, and the K270G mutant had dramatically decreased activity, although some reversal of coenzyme specificity was found. The positive effect of the R276H mutation was also observed when introduced into other single mutants: K270R/R276H and N272D/R276H. Since the K270R/N272D mutant corresponds to the best NADHpreferring $C t \mathrm{XR}$ mutant, K274R/N276D (Petschacher et al.,

Table 2. Specific activity and thermostability of WT and mutant PsXR

\begin{tabular}{|c|c|c|c|c|c|}
\hline \multirow[t]{2}{*}{ Enzyme } & \multirow[t]{2}{*}{ Coenzyme } & \multirow{2}{*}{$\begin{array}{l}\text { Specific activity } \\
\qquad\left(\mathrm{U} \mathrm{mg}^{-1}\right)\end{array}$} & \multirow{2}{*}{$\begin{array}{c}\text { NADH/ } \\
\text { NADPH ratio } \dagger\end{array}$} & \multicolumn{2}{|c|}{ Thermostability } \\
\hline & & & & $T_{\mathrm{m}}\left({ }^{\circ} \mathrm{C}\right) \ddagger$ & Activity $(\%) \S$ \\
\hline WT & $\begin{array}{l}\text { NADH } \\
\text { NADPH }\end{array}$ & $\begin{array}{r}7.2 \pm 0.4 \\
15.7 \pm 0.3\end{array}$ & 0.5 & $27.67 \pm 0.04$ & $4.1 \pm 0.3$ \\
\hline $\mathrm{K} 270 \mathrm{R}$ & $\begin{array}{l}\text { NADH } \\
\text { NADPH }\end{array}$ & $\begin{array}{l}6.7 \pm 0.0 \\
7.7 \pm 0.1\end{array}$ & 0.9 & $29.86 \pm 0.05(+2.19)$ & $2.4 \pm 0.1(-1.7)$ \\
\hline K270G & $\begin{array}{l}\text { NADH } \\
\text { NADPH }\end{array}$ & $\begin{array}{l}1.0 \pm 0.0 \\
0.5 \pm 0.0\end{array}$ & 2.0 & $32.40 \pm 0.08(+4.73)$ & $35.5 \pm 0.4(+31.4)$ \\
\hline $\mathrm{R} 276 \mathrm{H}$ & $\begin{array}{l}\text { NADH } \\
\text { NADPH }\end{array}$ & $\begin{array}{l}9.3 \pm 0.1 \\
0.4 \pm 0.0\end{array}$ & 23.1 & $36.43 \pm 0.06(+8.76)$ & $92.0 \pm 3.0(+87.9)$ \\
\hline K270R/R276H & $\begin{array}{l}\text { NADH } \\
\text { NADPH }\end{array}$ & $\begin{array}{l}3.5 \pm 0.0 \\
0.3 \pm 0.0\end{array}$ & 12.3 & $37.68 \pm 0.05(+10.01)$ & $79.9 \pm 1.3(+75.8)$ \\
\hline $\mathrm{N} 272 \mathrm{D} / \mathrm{R} 276 \mathrm{H}$ & $\begin{array}{l}\text { NADH } \\
\text { NADPH }\end{array}$ & $\begin{array}{l}9.3 \pm 0.5 \\
2.4 \pm 0.0\end{array}$ & 3.9 & $34.00 \pm 0.06(+6.33)$ & $52.8 \pm 1.3(+48.7)$ \\
\hline K270R/N272D & $\begin{array}{l}\text { NADH } \\
\text { NADPH }\end{array}$ & $\begin{array}{l}8.6 \pm 0.2 \\
3.0 \pm 0.0\end{array}$ & 2.9 & $32.75 \pm 0.05(+5.08)$ & $34.9 \pm 1.9(+30.8)$ \\
\hline K270R/N272D/R276H & $\begin{array}{l}\mathrm{NADH} \\
\mathrm{NADPH}\end{array}$ & $\begin{array}{l}7.4 \pm 0.0 \\
2.2 \pm 0.0\end{array}$ & 3.4 & $34.86 \pm 0.05(+7.19)$ & $53.6 \pm 4.6(+49.5)$ \\
\hline
\end{tabular}

${ }^{\star}$ Under standard assay conditions (see Methods).

$\dagger$ Specific activity with NADH/specific activity with NADPH.

$\ddagger \mathrm{CD}$ measurement. The difference from WT in $T_{\mathrm{m}}$ is shown in parentheses.

$\S$ Remaining activity after incubation at $30{ }^{\circ} \mathrm{C}$ for $10 \mathrm{~min}$. Relative value expressed as a percentage of the controls without heat treatment (100\%). For WT and K270R, NADPH was used as a coenzyme, while NADH was used for other enzymes. The difference from WT in remaining activity is shown in parentheses. 
2005), the significant acquisition of NADH preference is not unexpected.

Kinetic constants determined for coenzymes of WT and mutant PsXRs (R276H, K270R/N272D, K270R/R276H and K270R/N272D/R276H) are shown in Table 3. NADPH preference in the recombinant WT enzyme was mainly due to much higher affinity (lower $K_{\mathrm{m}}$ ) for $\mathrm{NADPH}$ than NADH. A high ratio of NADH/NADPH in $k_{\text {cat }} / K_{\mathrm{m}}$ was found for the R276H and K270R/N272D mutants: 2.62 and 7.29, respectively. Their kinetic constants for NADH were almost same as those of WT, although the K270R/N272D mutant showed an approximately 5 -fold higher $K_{\mathrm{m}}$ value with NADH. On the other hand, the $K_{\text {cat }} / K_{\mathrm{m}}$ values of the $\mathrm{R} 276 \mathrm{H}$ and K270R/N272D mutants with NADPH decreased 28- and 370-fold compared with WT; this was mainly due to a 40 -fold decrease in $K_{\text {cat }}$ and 1120 -fold increase in $K_{\mathrm{m}}$, respectively. When the $\mathrm{R} 276 \mathrm{H}$ mutation was introduced into the K270R/N272D mutant, no further improvement of $\mathrm{NADH}$ preference was seen. This may be due to an antagonistic effect by the introduction of two arginine residues, which may also account for a similar result found in the corresponding triple mutant of CtXR, K274R/N276D/R280H (Petschacher \& Nidetzky, 2005; Petschacher et al., 2005): the effect of steric hindrance on the $2^{\prime}$-phosphate group of $\mathrm{NADP}^{+}$, generated by the introduction of the side chain of $\mathrm{Arg}^{270}$, could be strongly reduced when the side chain of $\operatorname{Arg}^{276}$ is substituted by the smaller side chain of a histidine residue. By contrast, in our previous study using site-directed mutagenesis of $\mathrm{NAD}^{+}$dependent $P s \mathrm{XDH}$ for reversal of coenzyme specificity, novel $\mathrm{NADP}^{+}$-dependent activity in the best mutant, D207A/I208R/F209S/N211R, increased additionally via single, double and triple mutations (Watanabe et al., 2005). When compared with the WT, the R276H mutant showed similar $K_{\mathrm{m}}$ values with xylose in the presence of $\mathrm{NADH}$ or NADPH (Table 3). On the other hand, the
K270R/N272D mutant showed a 7.4-fold higher $K_{\mathrm{m}}$ value for xylose in the presence of NADPH.

\section{Effect of the modification of coenzyme specificity on thermostability}

The thermostability of WT and mutant PsXRs was estimated by monitoring the change in the CD signal at $220 \mathrm{~nm}$ at the thermal unfolding transition temperature $\left(T_{\mathrm{m}}\right)$. Overall, modification of coenzyme specificity towards NADH led to stabilization of PsXR, and the greatest thermostabilization was found in the $\mathrm{R} 276 \mathrm{H}$ single mutant (increase of $8.8{ }^{\circ} \mathrm{C}$ in $T_{\mathrm{m}}$ ) (Table 2). Furthermore, this mutation is also likely to stabilize when present with other single and double mutations. Similar results were obtained by heat treatment of the enzyme: the activity of the WT enzyme decreased to only $4.1 \%$ after incubation for $10 \mathrm{~min}$ at $30{ }^{\circ} \mathrm{C}$, whereas mutants containing the $\mathrm{R} 276 \mathrm{H}$ mutation maintained $50-90 \%$ of activity after the same treatment (Table 2). These results were unexpected because, as observed in several other dehydrogenases/ reductases (Chen et al., 1991; Grimshaw et al., 1992; Steen et al., 2002; Serov et al., 2002), the modification(s) of coenzyme specificity leads to a significant loss of thermostability. In fact, most $\mathrm{NADP}^{+}$-dependent mutants of PsXDH are more thermolabile than WT (Watanabe et al., 2005).

\section{Expression of PsXR mutants in S. cerevisiae}

To estimate the effect of modifying coenzyme specificity in $P s X R$ on ethanol fermentation from xylose, the respective XYL1 genes encoding the WT, R276H and K270R/N272D enzymes were each expressed in $S$. cerevisiae together with the XYL2 gene encoding WT PsXDH. Initially, both XYL1 and XYL2 genes were ligated to a yeast expression vector

Table 3. Kinetic parameters of WT and mutant PsXR

\begin{tabular}{|c|c|c|c|c|c|c|}
\hline Enzyme & Coenzyme & $K_{\mathrm{m}}^{*}(\boldsymbol{\mu M})$ & $k_{\text {cat }}{ }^{\star}\left(\min ^{-1}\right)$ & $\begin{array}{c}k_{\mathrm{cat}} / K_{\mathrm{m}}\left(\mu \mathrm{M}^{-1}\right. \\
\left.\min ^{-1}\right)\end{array}$ & $\begin{array}{c}\text { NADH/ } \\
\text { NADPH ratio } \\
\text { in } k_{\text {cat }} / K_{\mathrm{m}} \dagger\end{array}$ & $\begin{array}{c}K_{\mathrm{m}}(\text { xylose }) \\
(\mathrm{mM})\end{array}$ \\
\hline WT & NADPH & $2.5 \pm 0.1$ & $630 \pm 1$ & $260 \pm 11$ & & $47.0 \pm 0.1$ \\
\hline \multirow[t]{2}{*}{$\mathrm{R} 276 \mathrm{H}$} & NADH & $17.0 \pm 2.1$ & $408 \pm 15$ & $24.4 \pm 3.9$ & 2.62 & $45.5 \pm 0.2$ \\
\hline & NADPH & $1.7 \pm 0.1$ & $16.0 \pm 0.2$ & $9.3 \pm 0.4$ & & $53.2 \pm 0.5$ \\
\hline K270R/N272D & NADPH & $2810 \pm 480$ & $1850 \pm 310$ & $0.7 \pm 0.0$ & & $350 \pm 20$ \\
\hline \multirow[t]{2}{*}{ K270R/R276H } & $\mathrm{NADH}$ & $66 \pm 5$ & $58 \pm 4$ & $0.9 \pm 0.1$ & 0.30 & ND \\
\hline & NADPH & $2.7 \pm 0.2$ & $8.4 \pm 0.2$ & $3.1 \pm 0.3$ & & $\mathrm{ND}$ \\
\hline \multirow[t]{2}{*}{ K270R/N272D/R276H } & $\mathrm{NADH}$ & $41.8 \pm 9.1$ & $303 \pm 46$ & $7.4 \pm 0.5$ & 1.01 & $\mathrm{ND}$ \\
\hline & NADPH & $10.2 \pm 1.2$ & $74 \pm 3.9$ & $7.3 \pm 0.5$ & & ND \\
\hline
\end{tabular}

ND, Not determined.

${ }^{*}$ Six different concentrations of $\mathrm{NAD}(\mathrm{P}) \mathrm{H}$ between 50 and $300 \mu \mathrm{M}$ were used. The xylose concentration was $133 \mathrm{mM}$.

$\dagger\left(k_{\text {cat }} / K_{\mathrm{m}}\right.$ with $\left.\mathrm{NADH}\right) /\left(k_{\mathrm{cat}} / K_{\mathrm{m}}\right.$ with $\left.\mathrm{NADPH}\right)$. 
(pPGK) with the constitutive $P G K$ promoter (Kang et al., 1990). In the case of the XYL1 gene, the PsXR coding region with $P G K$ promoter and terminator was excised from the plasmid and reinserted into the YEpM4 vector (Nikawa et al., 1987). The resultant plasmids, pPGK containing the XYL2 gene and YEpM4 containing the XYL1 gene, were transformed into S. cerevisiae. XR and $\mathrm{XDH}$ activities in cell-free extracts prepared from yeast cells grown in minimal medium were measured spectrophotometrically (Fig. 1). Overall, significant $\mathrm{NADH}$ preference in reductase activity for xylose was found in cell-free extract prepared from recombinant $S$. cerevisiae cells expressing the NADH-preferring XR mutants, R276H or K270R/N272D. In contrast with the comparison using purified enzyme, the novel NADH-dependent activity in these mutants was higher than the NADPH-dependent activity in WT; this may be due to their thermostabilization (Table 2). XDH activities in these recombinant yeasts were observed at almost the same levels (Fig. 1). Little NADPHpreferring reduction of xylose and $\mathrm{NAD}^{+}$-dependent oxidization of xylitol were observed in the Y-Vector control, probably due to endogenous XR (YHR104W) (Träff et al., 2002) and XDH (YLR070C) (Richard et al., 1999).

\section{Batch fermentation}

Ethanol production and xylitol excretion of recombinant yeasts co-expressing NADH-preferring XR mutant (R276H or $\mathrm{K} 270 \mathrm{R} / \mathrm{N} 272 \mathrm{D}$ ) and $\mathrm{XDH}$ (WT) were preliminarily estimated by fermentation using shake-flask culture. One fermentation set $(100 \mathrm{ml})$ was started with 5 g glucose $\mathrm{l}^{-1}$

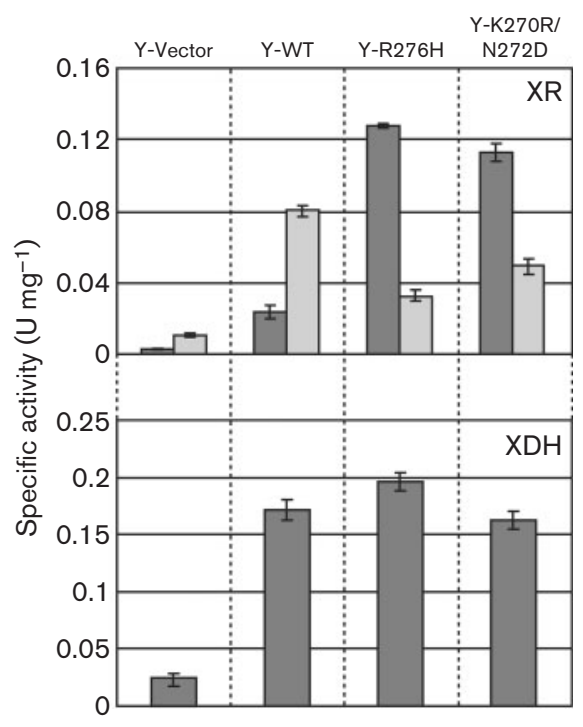

Fig. 1. Activities of $X R$ (top) and $X D H$ (bottom) in recombinant yeast strains. Dark-grey and light-grey bars indicate $\mathrm{NADH}-$ and $\mathrm{NADPH}$-dependent $\mathrm{XR}$ activities, respectively. $\mathrm{NAD}^{+}$was used as a coenzyme for $\mathrm{XDH}$ activity. Values are means $\pm \mathrm{SD}, n=3$. plus $15 \mathrm{~g}$ xylose $\mathrm{l}^{-1}$ (Fig. 2a). There was no significant difference between these recombinant yeast strains in the rate of cell growth (data not shown). In all these recombinant yeast strains, the glucose was initially consumed within $35 \mathrm{~h}$, and $37-46 \%$ of the xylose was fermented in $72 \mathrm{~h}$. Y-WT produced ethanol at $2.15 \mathrm{~g} \mathrm{l}^{-1}$ and excreted a relatively higher amount of xylitol $\left(1.45 \mathrm{gl}^{-1}\right)$. Y$\mathrm{R} 276 \mathrm{H}$ produced the highest amount of ethanol at $2.30 \mathrm{~g}$ $\mathrm{l}^{-1}$ and excreted the lowest amount of xylitol at $0.97 \mathrm{~g} \mathrm{l}^{-1}$. It is noteworthy that a more positive effect, particularly on xylitol excretion, was observed in Y-R276H rather than Y-K270R/N272D; this may be due to different adaptation for $\mathrm{NADH}$ of these enzymes in vitro as described above.
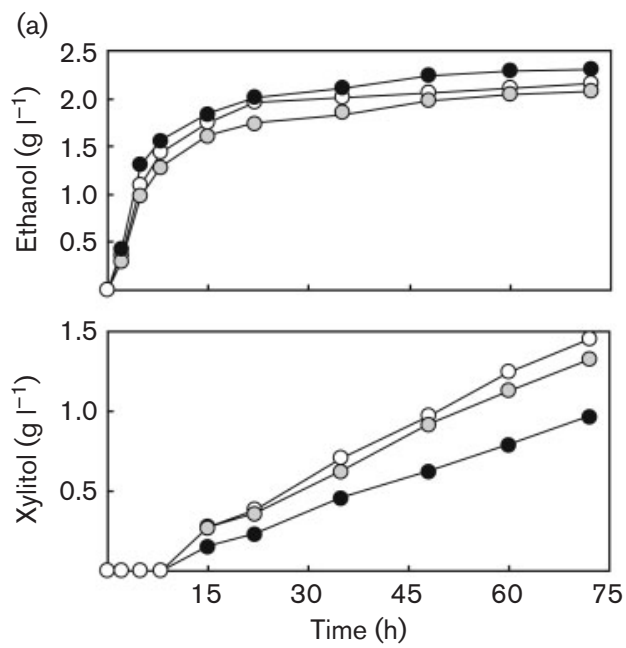

(b)

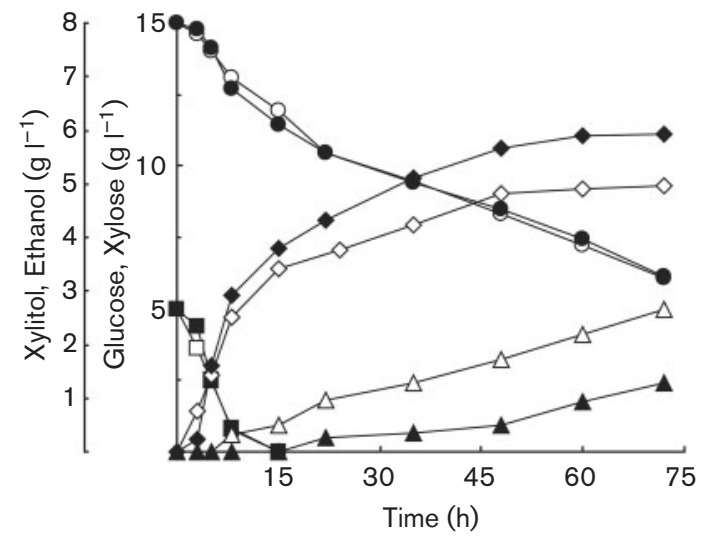

Fig. 2. Ethanol fermentation by recombinant $S$. cerevisiae in minimal medium supplemented with glucose $\left(5 \mathrm{~g} \mathrm{I}^{-1}\right)$ and xylose $\left(15 \mathrm{~g} \mathrm{l}^{-1}\right)$. Values are the means of the results of duplicate experiments which differed by less than $10 \%$. (a) Ethanol (top) and xylitol (bottom) production profiles during batch fermentation in a shake flask by Y-WT (white), R276H (black) and K270R/N272D (grey). (b) Batch fermentation in a bioreactor under the same conditions as in (a) by Y-WT (white symbols) and Y-R276H (black symbols). Concentrations of glucose (squares), xylose (circles), xylitol (triangles) and ethanol (diamonds) are shown. 
The fermentation by $\mathrm{Y}-\mathrm{R} 276 \mathrm{H}$ was further investigated using a bioreactor under the same conditions as for the shake-flask culture and compared with that by Y-WT (Fig. 2b). Y-R276H produced ethanol at $5.94 \mathrm{~g} \mathrm{l}^{-1}$ with a yield of $0.43 \mathrm{~g}$ ethanol per $\mathrm{g}$ total consumed sugars, which reached $84 \%$ of the theoretical yield. Of the xylose, $59 \%$ was consumed in $72 \mathrm{~h}$ and xylitol excretion was $1.29 \mathrm{~g} \mathrm{l}^{-1}$. Compared with Y-WT, a $20 \%$ increase in ethanol production and a $52 \%$ decrease in xylitol excretion were observed in fermentation by $\mathrm{Y}-\mathrm{R} 276 \mathrm{H}$. These results indicated that this protein-engineering approach is useful for the fermentation of xylose to ethanol using $S$. cerevisiae.

\section{Intracellular coenzyme levels}

We measured the intracellular concentrations of NADH, $\mathrm{NAD}^{+}, \mathrm{NADPH}$, and $\mathrm{NADP}^{+}$in cells of recombinant strains in the late exponential growth phase (Table 4). No significant differences in the concentrations of the four coenzymes were observed between samples in early, middle and late exponential growth phases (data not shown). Intracellular redox states were estimated by the ratios of $\mathrm{NADH} / \mathrm{NAD}^{+}$and $\mathrm{NADPH} / \mathrm{NADP}^{+}$(referred to as $R_{\mathrm{NAD}(\mathrm{H})}$ and $R_{\mathrm{NADP}(\mathrm{H})}$, respectively). When compared with Y-Vector, the $R_{\mathrm{NADP}(\mathrm{H})}$ of Y-WT was threefold higher, while $R_{\mathrm{NAD}(\mathrm{H})}$ was twofold less. It is noteworthy that $\mathrm{Y}$ $\mathrm{R} 276 \mathrm{H}$ has $R_{\mathrm{NAD}(\mathrm{H})}$ and $R_{\mathrm{NADP}(\mathrm{H})}$ values more similar to $\mathrm{Y}-\mathrm{Vector}$ than does Y-WT, indicating that the NADHpreferring mutation in PsXR led to maintenance of redox balance in yeast cells.

\section{DISCUSSION}

\section{Reversal of coenzyme specificity of PsXR}

Since $P s \mathrm{XR}$ shows high sequence similarity to $C t \mathrm{XR}$ $(\sim 77 \%)$, the kinetic and crystallographic characterization of $\mathrm{NADH}$-preferring $\mathrm{CtXR}$ is useful for estimating the effects of K270R/N272D and R276H mutations, which gave the most significant reversal of coenzyme specificity in this study. The K274R/N276D CtXR mutant corresponds to the K270R/N272D PsXR mutant and shows the best ratio of $\mathrm{NADPH} / \mathrm{NADH}$ in $k_{\mathrm{cat}} / K_{\mathrm{m}}(0.2)$, compared with that of WT (33) (Petschacher et al., 2005). This improvement is mainly due to a dramatic decrease of binding affinity to $\mathrm{NADPH}$, compared with that in WT. A similar tendency is also found in the K270R/N272D mutant PsXR (Table 3). Crystallographic studies revealed that both the native enzyme and K274R/N276D CtXR mutant interact with $\mathrm{NAD}^{+}$(probably also with $\mathrm{NADH}$ ) in a very similar manner (Kavanagh et al., 2003; Petschacher et al., 2005): the responsibility for the NADH preference in these mutations of $C t \mathrm{XR}$ and $P s \mathrm{XR}$ remains unclear. However, XR from C. parapsilosis (Lee et al., 2003) natively possesses arginine at a position equivalent to $\mathrm{Lys}^{274}$ and $\mathrm{Lys}^{270}$ in $C$. tenuis and P. stipitis XRs, respectively, indicating that this Lys $\rightarrow$ Arg substitution may at least be physiological (Table 1). The $\mathrm{R} 280 \mathrm{H}$ mutation in $\mathrm{CtXR}$, corresponding to the $\mathrm{R} 276 \mathrm{H}$ mutation in PsXR, leads to an eightfold decrease in the ratio of $\mathrm{NADPH} / \mathrm{NADH}$ in $k_{\mathrm{cat}} / K_{\mathrm{m}}$, although the enzyme still shows a fourfold NADPH preference (Petschacher \& Nidetzky, 2005). Since the side-chain of $\mathrm{Arg}^{280}$ interacts with the 2'-position of adenosine ribose more strongly in the $\mathrm{CtXR}-\mathrm{NADP}^{+}$ complex than in the CtXR-NAD ${ }^{+}$complex (Kavanagh et al., 2003, 2002), the R $280 \mathrm{H}$ mutation, which removes the contact mediated by the guanidinium group of arginine, may effect an NADPH-linked rather than NADH-linked enzyme reaction. In fact, when compared with $\mathrm{WT}$, the kinetic parameters with $\mathrm{NADH}$ of the $\mathrm{R} 276 \mathrm{H}$ mutant of PsXR are similar, while the $k_{\text {cat }}$ value for NADPH decreases dramatically, by 40 -fold (Table 3 ). Overall, it is likely that the $\mathrm{K} 270 \mathrm{R} / \mathrm{N} 272 \mathrm{D}$ and $\mathrm{R} 276 \mathrm{H}$ mutants of PsXR are responsible for $\mathrm{NADPH}$ preference in a similar manner to the K274R/N276D and R280H mutants of CtXR.

\section{Thermostabilization of PsXR}

Most of the modifications of coenzyme specificity of PsXR led to simultaneous stabilization of the mutant enzymes (Table 2). In particular, the $\mathrm{R} 276 \mathrm{H}$ single mutant maintains almost full activity after heat treatment at $30{ }^{\circ} \mathrm{C}$ for $10 \mathrm{~min}$, while the WT enzyme is inactivated completely under the same conditions. This result was unexpected because most mutations tend to affect the stability of the protein neutrally or negatively. Since XR is composed of two identical subunits, thermostabilization may potentially be achieved by strengthening intermolecular and/or intersubunit interaction(s). In the crystal

Table 4. Intracellular concentration of coenzymes in recombinant yeast cells

\begin{tabular}{|c|c|c|c|c|c|c|}
\hline \multirow[t]{2}{*}{ Strain } & \multicolumn{4}{|c|}{ Intracellular concn $\left[\mu \mathrm{mol}(\mathrm{g} \text { dry wt of biomass })^{-1}\right]$} & \multirow[t]{2}{*}{$R_{\mathrm{NAD}(\mathrm{H})^{*}}$} & \multirow[t]{2}{*}{$\boldsymbol{R}_{\mathrm{NADP}(\mathrm{H})} \dagger$} \\
\hline & $\mathrm{NAD}^{+}$ & NADH & NADP $^{+}$ & NADPH & & \\
\hline Y-Vector & $6.58 \pm 0.11$ & $3.19 \pm 0.29$ & $3.41 \pm 0.18$ & $5.24 \pm 0.01$ & 0.49 & 1.54 \\
\hline Y-WT & $8.26 \pm 0.16$ & $2.69 \pm 0.08$ & $1.68 \pm 0.04$ & $8.24 \pm 0.14$ & 0.33 & 4.92 \\
\hline Y-R276H & $7.39 \pm 0.28$ & $4.06 \pm 0.04$ & $2.02 \pm 0.01$ & $7.15 \pm 0.09$ & 0.55 & 3.54 \\
\hline
\end{tabular}

${ }^{\star}$ Ratio of $\mathrm{NADH} / \mathrm{NAD}^{+}$.

$\dagger$ Ratio of NADPH/NADP ${ }^{+}$. 
structure of the CtXR apo-form, a side-chain of the equivalent arginine to $\mathrm{Arg}^{276}$ in $P s \mathrm{XR}$ forms no interaction with another amino acid residue, although there is a hydrogen bond with $-\mathrm{NH}$ of $\mathrm{Arg}^{276} \mathrm{C} \alpha$ and $-\mathrm{CO}$ of $\mathrm{Leu}^{277}$ $\mathrm{C} \alpha$ (Kavanagh et al., 2002). This arginine is contained within a very flexible coenzyme-binding loop, which is located separately from the subunit-subunit interface in dimeric CtXR. On the other hand, Klimacek et al. (2003) reported that the R180A mutation of $C t \mathrm{XR}$, which is located within the subunit-subunit interface, leads to destabilization of the protein without changing the dimeric form. Interestingly, the NADH-dependent activity of this mutant is one-third of the WT level, mainly due to a 2.5 -fold decrease of $k_{\text {cat }}$ for NADH, although significant NADPH preference was still maintained as well as WT. These results suggest that modifications at the subunit-subunit interface have long-range effects on enzyme catalytic function(s) and that the R276H mutant of PsXR in this study is stabilized by such a mechanism(s) because this mutation leads to the modification of coenzyme specificity toward NADH (but not NADPH) (Tables 2 and 3 ).

\section{Effect of NADH-preferring XR mutant on ethanol fermentation}

The typical unfavourable excretion of xylitol in ethanol fermentation from xylose using recombinant $S$. cerevisiae has been ascribed to the difference in coenzyme utilization in NADPH-preferring $\mathrm{XR}$ and strict $\mathrm{NAD}^{+}$-dependent $\mathrm{XDH}$ reactions (Jeffries \& Jin, 2004). Therefore, many researchers have targeted the production and consumption of NADPH/NADP ${ }^{+}$and NADH/NAD ${ }^{+}$using recombinant yeast co-expressing WT enzymes, $P s X \mathrm{X}$ and $P s \mathrm{XDH}$ : disruption of the ZWF1 gene encoding glucose-6-phosphate dehydrogenase (Jeppsson et al., 2002); overexpression of a cytoplasmic transhydrogenase, catalysing the conversion of $\mathrm{NAD}^{+}$and NADPH into NADH and $\mathrm{NADP}^{+}$, respectively (Nissen et al., 2001); overproduction of $\mathrm{NADP}^{+}$-dependent glyceraldehyde-3-phosphate dehydrogenase (Verho et al., 2003); and disruption of the GDH1 gene encoding NADPH-dependent glutamate dehydrogenase in ammonium assimilation (Roca et al., 2003). These metabolic modifications generally lead to reduction of the intracellular NADPH pool to improve ethanol production and xylitol excretion.

Alternatively, for the same purpose, there are few reports on the protein-engineering approach to $\mathrm{XR}$ and $\mathrm{XDH}$, as described in the Introduction; therefore, one of the most significant insights in this study is the relationship between the modification of coenzyme specificity of xylosemetabolizing enzyme (in vitro) and ethanol fermentation from xylose using the mutated enzyme(s) (in vivo). Jeppsson et al. (2006) estimated the effect on xylose fermentation of a PsXR K270M mutant with a higher $K_{\mathrm{m}}$ for NADH. In the recombinant $S$. cerevisiae carrying the mutated PsXR (referred to as Y-K270M), xylitol and glycerol yields decreased $24 \%$ and $50 \%$, respectively, while only $11 \%$ increase in ethanol yield was observed. On the other hand, in S. cerevisiae Y-R276H, improvement of xylitol and ethanol yields was much higher than that in YK270M ( $32 \%$ and $58 \%$, respectively), while no significant change was found in glycerol yield (Supplementary Table S2). The main reason for this difference must be different adaptation for NADPH between the R276H and $\mathrm{K} 270 \mathrm{M}$ PsXR mutants: the former shows 26-fold lower $k_{\text {cat }}$ for $\mathrm{NADPH}$ than $\mathrm{NADH}$ in the R276H mutant (Table 3), while the latter shows 17 -fold higher $K_{\mathrm{m}}$ for $\mathrm{NADH}$ and unchanged $K_{\mathrm{m}}$ for NADPH (Kostrzynska et al., 1998), which is analogous to the K270R/N272D mutant. In fact, Y-K270R/N272D has no advantage over Y-R276H in xylose fermentation (Fig. 2a). The intracellular concentration of NADPH decreases by $13 \%$ in Y-R276H, while that of NADH increases by $51 \%$, compared with that of Y-WT (Table 4). Similar tendencies are observed in Y-K270M (Jeppsson et al., 2006). These results indicate that the two strains harbouring the NADH-preferring XR mutant utilize a larger fraction of NADH for the reduction of xylose.

As described in the Introduction, an alternative strategy for maintaining intracellular redox balance is to utilize the xylose-fermenting pathway via XI. Recently, it was first reported that XI from the fungus Piromyces sp. strain E3 resulted in significant activity in S. cerevisiae cells (Kuyper et al., 2003). However, comparison of xylose-fermenting ability by XR-XDH- and XI-carrying recombinant $S$. cerevisiae strains revealed that the $\mathrm{XR}-\mathrm{XDH}$ xylose utilization pathway is much better than the XI pathway (Karhumaa et al., 2007). In this study, we introduced only exotic XYL1 and XYL2 genes into S. cerevisiae. On the other hand, in addition to the metabolic engineering described above, the introduction and overexpression of other endogenous genes, including xylulokinase $(X K)$, transketolase (TKL1), transaldolase (TAL1) and several hexose-transporter (HXT1-7) genes, have been attempted to enhance the pentosephosphate pathway and/or xylose uptake (Jeffries \& Jin, 2004). Combined approaches of these strategies and our strategy using the protein-engineered enzyme should be considered to achieve more effective ethanol production from xylose by recombinant $S$. cerevisiae.

\section{ACKNOWLEDGEMENTS}

This work was supported by a Grant-in-Aid for Young Scientists (B) (no. 18760592 to S. W.), the Center of Excellence (COE) program for the 'Establishment of COE on Sustainable Energy System', a Grant-inAid for Scientific Research, and Grants for Regional Science and Technology Promotion 'Kyoto Nanotechnology Cluster' project, from the Ministry of Education, Science, Sports and Culture, Japan. This work was also supported by CREST and 'Research for Promoting Technological Seeds' of the Japan Science and Technology Corporation.

\section{REFERENCES}

Banta, S., Swanson, B. A., Wu, S., Jarnagin, A. \& Anderson, S. (2002a). Alteration of the specificity of the cofactor-binding pocket of 
Corynebacterium 2,5-diketo-D-gluconic acid reductase A. Protein Eng 15, 131-140.

Banta, S., Swanson, B. A., Wu, S., Jarnagin, A. \& Anderson, S. (2002b). Optimizing an artificial metabolic pathway: engineering the cofactor specificity of Corynebacterium 2,5-diketo-D-gluconic acid reductase for use in vitamin C biosynthesis. Biochemistry 41, 6226-6236.

Bergmeyer, H. U. (1985). Nicotinamide-adenine dinucleotides and dinucleotide phosphates (NAD, NADP, NADH, NADPH). In Methods of Enzymatic Analysis, 3rd edn, vol. VII. Weinheim: VCH.

Chen, Z., Lee, W. R. \& Chang, S. H. (1991). Role of aspartic acid 38 in the cofactor specificity of Drosophila alcohol dehydrogenase. Eur $J$ Biochem 202, 263-267.

Ellis, E. M. (2002). Microbial aldo-keto reductases. FEMS Microbiol Lett 216, 123-131.

Gietz, D., St Jean, A., Woods, R. A. \& Schiestl, S. H. (1992). Improved method for high efficiency transformation of intact yeast cells. Nucleic Acids Res 20, 1425.

Grimshaw, C. E., Matthews, D. A., Varughese, K. I., Skinner, M., Xuong, N. H., Bray, T., Hoch, J. \& Whiteley, J. M. (1992). Catalytic effectiveness of human aldose reductase: critical role of C-terminal domain. J Biol Chem 267, 15334-15339.

Jeffries, T. W. (1983). Utilization of xylose by bacteria, yeasts, and fungi. Adv Biochem Eng Biotechnol 27, 1-32.

Jeffries, T. W. (1985). Emerging technology for fermenting D-xylose. Trends Biotechnol 3, 208-212.

Jeffries, T. W. \& Jin, Y. S. (2004). Metabolic engineering for improved fermentation of pentoses by yeasts. Appl Microbiol Biotechnol 63 , 495-509.

Jeppsson, M., Johansson, B., Hahn-Hägerdal, B. \& GorwaGrauslund, M. F. (2002). Reduced oxidative pentose phosphate pathway flux in recombinant xylose-utilizing Saccharomyces cerevisiae strains improves the ethanol yield from xylose. Appl Environ Microbiol 68, 1604-1609.

Jeppsson, M., Bengtsson, O., Katja, F., Lee, H., Hahn-Hägerdal, B. \& Gorwa-Grauslund, M. F. (2006). The expression of a Pichia stipitis xylose reductase mutant with higher $K_{\mathrm{M}}$ for NADPH increases ethanol production from xylose recombinant Saccharomyces cerevisiae. Biotechnol Bioeng 93, 665-673.

Kang, Y. S., Kane, J., Kurjan, K., Stadel, J. M. \& Tipper, D. J. (1990). Effects of expression of mammalian $\mathrm{G} \alpha$ and hybrid mammalian-yeast $\mathrm{G} \alpha$ proteins on the yeast pheromone response signal transduction pathway. Mol Cell Biol 10, 2582-2590.

Karhumaa, K., Sanchez, R. G., Hahn-Hägerdal, B. \& GorwaGrauslund, M. F. (2007). Comparison of the xylose reductase-xylitol dehydrogenase and the xylose isomerase pathways for xylose fermentation by recombinant Saccharomyces cerevisiae. Microb Cell Fact 6, 5.

Kavanagh, K. L., Klimacek, M., Nidetzky, B. \& Wilson, D. K. (2002). The structure of apo and holo forms of xylose reductase, a dimeric aldo-keto reductase from Candida tenuis. Biochemistry 41, 8785-8795.

Kavanagh, K. L., Klimacek, M., Nidetzky, B. \& Wilson, D. K. (2003). Structure of xylose reductase bound to $\mathrm{NAD}^{+}$and the basis for single and dual co-substrate specificity in family 2 aldo-keto reductases. Biochem J 373, 319-326.

Klimacek, M., Wuhrer, F., Kavanagh, K. L., Wilson, D. K. \& Nidetzky, B. (2003). Altering dimer contacts in xylose reductase from Candida tenuis by site-directed mutagenesis: structural and functional properties of R180A mutant. Chem Biol Interact 143-144, 523-532.

Kostrzynska, M., Sopher, C. R. \& Lee, H. (1998). Mutational analysis of the role of the conserved lysine-270 in the Pichia stipitis xylose reductase. FEMS Microbiol Lett 159, 107-112.
Kurtzman, C. P. (1994). Molecular taxonomy of the yeasts. Yeast 10, 1727-1740.

Kuyper, M., Harhangi, H. R., Stave, A. K., Winkler, A. A., Jetten, M. S., de Laat, W. T., den Ridder, J. J., Op den Camp, H. J., van Dijken, J. P. \& Pronk, J. T. (2003). High-level functional expression of a fungal xylose isomerase: the key to efficient ethanolic fermentation of xylose by Saccharomyces cerevisiae? FEMS Yeast Res 4, 69-78.

Laemmli, U. K. (1970). Cleavage of structural proteins during the assembly of the head of bacteriophage T4. Nature 227, 680-685.

Lee, J. K, Koo, B. S. \& Kim, S. Y. (2003). Cloning and characterization of the xyll gene, encoding an NADH-preferring xylose reductase from Candida parapsilosis, and its functional expression in Candida tropicalis. Appl Environ Microbiol 69, 6179-6188.

Leitgeb, S., Petschacher, B., Wilson, D. K. \& Nidetzky, B. (2005). Fine tuning of coenzyme specificity in family 2 aldo-keto reductases revealed by crystal structures of the Lys-274 $\rightarrow$ Arg mutant of Candida tenuis xylose reductase (AKR2B5) bound to $\mathrm{NAD}^{+}$and $\mathrm{NADP}^{+}$. FEBS Lett 579, 763-767.

Metzger, M. H. \& Hollenberg, C. P. (1995). Amino acid substitutions in the yeast Pichia stipitis xylitol dehydrogenase coenzyme-binding domain affect the coenzyme specificity. Eur J Biochem 228, 50-54.

Nikawa, J., Sass, P. \& Wigler, M. (1987). Cloning and characterization of the low-affinity cyclic AMP phosphodiesterase gene of Saccharomyces cerevisiae. Mol Cell Biol 7, 3629-3636.

Nissen, T. L., Anderlund, M., Nielsen, J., Villadsen, J. \& KiellandBrandt, M. C. (2001). Expression of a cytoplasmic transhydrogenase in Saccharomyces cerevisiae results in formation of 2-oxoglutarate due to depletion of the NADPH pool. Yeast 18, 19-32.

Petschacher, B. \& Nidetzky, B. (2005). Engineering Candida tenuis xylose reductase for improved utilization of NADH: antagonistic effects of multiple side chain replacements and performance of sitedirected mutants under simulated in vivo conditions. Appl Environ Microbiol 71, 6390-6393.

Petschacher, B., Leitgeb, S., Kavanagh, K. L., Wilson, D. K. \& Nidetzky, B. (2005). The coenzyme specificity of Candida tenuis xylose reductase (AKR2B5) explored by site-directed mutagenesis and X-ray crystallography. Biochem J 385, 75-83.

Richard, P., Toivari, M. H. \& Penttilä, M. (1999). Evidence that the gene YLR070c of Saccharomyces cerevisiae encodes a xylitol dehydrogenase. FEBS Lett 457, 135-138.

Rizzi, M., Harwart, K., Erlemann, P., Buithanh, N. A. \& Dellweg, H. (1989). Purification and properties of the $\mathrm{NAD}^{+}$-xylitol-dehydrogenase from the yeast Pichia stipitis. J Ferment Bioeng 67, 20-24.

Roca, C., Nielsen, J. \& Olsson, L. (2003). Metabolic engineering of ammonium assimilation in xylose-fermenting Saccharomyces cerevisiae improves ethanol production. Appl Environ Microbiol 69, 4732-4736.

Serov, A. E., Popova, A. S., Fedorchuk, V. V. \& Tishkov, V. I. (2002). Engineering of coenzyme specificity of formate dehydrogenase from Saccharomyces cerevisiae. Biochem J 367, 841-847.

Steen, I. H., Lien, T., Madsen, M. S. \& Birkeland, N. K. (2002). Identification of cofactor discrimination sites in NAD-isocitrate dehydrogenase from Pyrococcus furiosus. Arch Microbiol 178, 297-300.

Träff, K. L., Jönsson, L. J. \& Hahn-Hägerdal, B. (2002). Putative xylose and arabinose reductases in Saccharomyces cerevisiae. Yeast 19, 1233-1241.

Verduyn, C., Van Kleef, R., Frank, J., Schreuder, H., Van Dijken, J. P. \& Scheffers, W. A. (1985). Properties of the NAD(P)H-dependent xylose reductase from the xylose-fermenting yeast Pichia stipitis. Biochem J 226, 669-677.

Verho, R., Londesborough, J., Penttilä, M. \& Richard, P. (2003). Engineering redox cofactor regeneration for improved pentose 
fermentation in Saccharomyces cerevisiae. Appl Environ Microbiol 69, 5892-5897.

Watanabe, S., Kodaki, T. \& Makino, K. (2005). Complete reversal of coenzyme specificity of xylitol dehydrogenase and increase of thermostability by the introduction of structural zinc. J Biol Chem 280, 10340-10349.
Watanabe, S., Saleh, A. A., Pack, S. P., Annaluru, N., Kodaki, T. \& Makino, K. (2007). Ethanol production from xylose by recombinant Saccharomyces cerevisiae expressing protein engineered $\mathrm{NADP}^{+}$. dependent xylitol dehydrogenase. J Biotechnol 130, 316-319.

Edited by: M. Schweizer 